\title{
Логико-информационные модели как основа для экспресс-оценки потенциальных Au-Ag эпитермальных месторождений
}

\author{
Чижова И.А., Волков А.В., Шелястина Е.В. \\ Институт геологии рудных месторождений, петрографии, минералогии и геохимии РАН, Москва, \\ tchijova@igem.ru
}

Аннотация. Детальный логико-информационный анализ геохимических данных по эталонным $\mathrm{Au}-\mathrm{Ag}$ эпитермальным месторождениям позволил построить модели для их 11 рудноформационных подтипов (по А.В. Волкову), выделенных на основе изучения месторождений золота Северо-Востока России. Алгоритм допускает корректное применение для идентификации рудноформационного подтипа новых рудопроявлений золота в Арктической зоне России с высокой степенью надежности (96 \%). Разработана экспертная система в виде Excel-модуля для идентификации новых объектов.

Ключевые слова: Au-Ag эпитермальные месторождения, Северо-Восток России, Арктическая зона, логикоинформационная модель, база данных, рудноформационный тип, микроэлементы, прогноз, экспресс-оценка.

\section{Logical-information models as the base for rapid assessment of potential Au-Ag epithermal deposits}

\section{Chizhova I.A., Volkov A.V., Shelyastina E.V.}

Institute of Geology of Ore Deposits, Petrography, Mineralogy, and Geochemistry of the Russian Academy of Sciences, Moscow,tchijova@igem.ru

\begin{abstract}
The detailed logical-information analysis of the geochemical data for etalon $\mathrm{Au}-\mathrm{Ag}$ epithermal deposits has allowed to construct the models for their 11 ore formation subtypes (by A.V.Volkov), which were determined using the gold deposits allocated Northeast of Russia. The algorithm has allowed the correct application at identification of ore formation subtype for new gold occurrences with a high degree of reliability (96\%) and may be used in the Arctic zone of Russia. The expert system as the Excel-module for identification of new objects has been designed.

Key words: Au-Ag epithermal deposits, Northeast of Russia, the Arctic zone, logical-information model, database, ore-formation type, trace elements, forecast, rapid assessment.

\section{Введение}

Определение рудноформационного типа оруденения и его масштабности - важные задачи в процессе выявления перспективных площадей. От правильного их решения зависит выбор направления и эффективной методики проведения геологоразведочных работ (ГРР). Процедуры экспрессоценки месторождений с использованием компьютерного анализа данных способствуют ускорению разбраковки выделенных участков, что весьма важно при проведении ГРР. Поэтому они так необходимы для расширения минерально-сырьевой базы золота России, особенно ее северо-восточных арктических регионов.

Особое внимание уделяется информационному подходу к решению прогнозных задач и экспресс-оценке различных параметров месторождений с целью выявления наиболее перспективных для освоения и разработки (Поднебесных А.В., Хафизов А.P., 2019; Schnitzler et al., 2019; Kaplan and Topal, 2020). Среди новейших технологий наибольшей востребованностью обладают методы искусственного интеллекта и машинное обучение (Zhang et al., 2019).

Более точное определение рудноформационного типа объекта оценки позволяет подобрать для него наиболее близкий объект-аналог из эталонных месторождений данного типа, а значит, по методу аналогии, более точно предположить возможную масштабность нового объекта. Поэтому была поставлена задача определения подтипа Au-Ag эпитермальных месторождений с учетом формационного типа, рудного комплекса и тектоно-металлогенической обстановки. Такая типизация $\mathrm{Au}-\mathrm{Ag}$ эпитермальных месторождений ранее была проведена А.В. Волковым (табл. 1).
\end{abstract}


Целью данной работы являлось выявление особенностей выделенных 11 групп месторождений и создание на их основе процедуры экспресс-оценки перспективных площадей.

Таблица 1. Типизация Au-Ag эпитермальных месторождений (по А.В. Волкову).

Table 1. Typification of Au-Ag epithermal deposits (by A.V. Volkov).

\begin{tabular}{|c|c|c|c|c|c|}
\hline № & $\begin{array}{c}\text { Формационный } \\
\text { тип }\end{array}$ & $\begin{array}{c}\text { Рудный } \\
\text { комплекс }\end{array}$ & $\begin{array}{c}\text { Тектоно-металлогеническая } \\
\text { обстановка }\end{array}$ & $\begin{array}{c}\text { Примеры эталонных место- } \\
\text { рождений в базе данных }\end{array}$ & $\begin{array}{l}\text { Число } \\
\text { проб }\end{array}$ \\
\hline 1 & HS & IRGS & $\begin{array}{l}\text { Кедонский средне-палеозойский вул- } \\
\text { канический пояс, Омолонский кра- } \\
\text { тонный террейн }\end{array}$ & Юное & 5 \\
\hline 2 & $\begin{array}{c}\mathrm{LS} \\
\mathrm{Au} / \mathrm{Ag}=1 / 1-1 / 3\end{array}$ & IRGS & $\begin{array}{l}\text { Кедонский средне-палеозойский вул- } \\
\text { канический пояс, Омолонский кра- } \\
\text { тонный террейн }\end{array}$ & $\begin{array}{c}\text { Кубака, Цоколь*, Бирка- } \\
\text { чан, Бургали, Южное Бур- } \\
\text { гали, Магнитный }\end{array}$ & 26 \\
\hline 3 & $\begin{array}{c}\mathrm{LS} \mathrm{Au} / \mathrm{Ag}=1 / 3- \\
1 / 10\end{array}$ & $\begin{array}{l}\text { Cu-Mo- } \\
\text { Porph }\end{array}$ & $\begin{array}{l}\text { Кедонский средне-палеозойский вул- } \\
\text { канический пояс, Омолонский кра- } \\
\text { тонный террейн }\end{array}$ & Ольча & 6 \\
\hline 4 & $\begin{array}{c}\mathrm{LS} \mathrm{Au} / \mathrm{Ag}=1 / 3- \\
1 / 10\end{array}$ & $\begin{array}{l}\text { Cu-Mo- } \\
\text { Porph }\end{array}$ & $\begin{array}{l}\text { ОЧВП, террейн пассивной континен- } \\
\text { тальной окраины }\end{array}$ & $\begin{array}{l}\text { Джульетта, Тихое, } \\
\text { Нявленга, Дальнее }\end{array}$ & 22 \\
\hline 5 & $\begin{array}{c}\mathrm{LS} \mathrm{Au} / \mathrm{Ag}=1 / 3- \\
1 / 10\end{array}$ & Sn-Porph & $\begin{array}{l}\text { ОЧВП, террейн пассивной континен- } \\
\text { тальной окраины }\end{array}$ & $\begin{array}{c}\text { Ойра, Печальное, } \\
\text { Ущельное, Аган, Утесное* }\end{array}$ & 23 \\
\hline 6 & $\stackrel{\mathrm{LS}}{\mathrm{Au} / \mathrm{Ag}=1 / 3-1 / 10}$ & $\begin{array}{l}\text { Cu-Mo- } \\
\text { Porph }\end{array}$ & $\begin{array}{l}\text { Анадырский сектор ОЧВП, Олойский } \\
\text { островодужный террейн }\end{array}$ & $\begin{array}{l}\text { Купол, Морошка, } \\
\text { Телевеем }\end{array}$ & 13 \\
\hline 7 & $\begin{array}{c}\mathrm{LS} \\
\mathrm{Au} / \mathrm{Ag}=1 / 3-1 / 10\end{array}$ & $\begin{array}{l}\text { Cu-Mo- } \\
\text { Porph }\end{array}$ & $\begin{array}{l}\text { Анадырский сектор ОЧВП, террейн } \\
\text { пассивной континентальной окраины }\end{array}$ & Двойное & 6 \\
\hline 8 & $\mathrm{IS}$ & $\begin{array}{l}\text { Cu-Mo- } \\
\text { Porph }\end{array}$ & $\begin{array}{l}\text { Анадырский сектор ОЧВП, террейн } \\
\text { пассивной континентальной окраины }\end{array}$ & Сентябрьское & 6 \\
\hline 9 & $\mathrm{IS} ; \mathrm{Au} / \mathrm{Ag}>1 / 100$ & Sn-Porph & $\begin{array}{l}\text { Балыгычан-Сугойский рифтогенный } \\
\text { прогиб, ОЧВП }\end{array}$ & Дукат, Лунное*, Теплое & 15 \\
\hline 10 & $\begin{array}{c}\mathrm{LS} \\
\mathrm{Au} / \mathrm{Ag}=1 / 10- \\
1 / 100\end{array}$ & Sn-Porph & $\begin{array}{l}\text { Анадырский сектор ОЧВП, террейн } \\
\text { пассивной континентальной окраины }\end{array}$ & Пепенвеем, Эргувеем & 11 \\
\hline \multirow[t]{3}{*}{11} & $\begin{array}{c}\mathrm{LS} \\
\mathrm{Au} / \mathrm{Ag}=1 / 3-1 / 10\end{array}$ & $\begin{array}{l}\text { Cu-Mo- } \\
\text { Porph }\end{array}$ & $\begin{array}{l}\text { Камчатская островная дуга, кайно- } \\
\text { зойские вулканические пояса, офио- } \\
\text { литы }\end{array}$ & Аметистовый, Родниковое & 13 \\
\hline & & & & Всего проб & 146 \\
\hline & & & & Прогнозные площади (13) & 77 \\
\hline
\end{tabular}

Примечание. * - данные по этим трем объектам в расчетах не участвовали.

\section{Методика исследований}

В рудообразующих системах, распространенных на Северо-Востоке России, присутствует большое разнообразие месторождений золота, особенности которых можно охарактеризовать специфическими наборами микроэлементов (Волков и др., 2017).

Математическое моделирование на базе машинного обучения позволяет автоматизировать процесс их поиска. В качестве способа выделения системы информативных признаков с указанием их разделяющих весов и диапазонов изменения значений (интервалов-индикаторов), типичных для месторождений золота конкретного рудноформационного типа (подтипа), был использован логикоинформационный анализ (Чижова, 2010). 
Ранее проводилась работа по выявлению особенностей 5 типов руд различных формаций: $\mathrm{Au}-\mathrm{Ag}$ эпитермальная; Аu-кварцевая; Аu-сульфидная; Cu-Мо-Аu-порфировая; $\mathrm{Au-колчеданная}$ (Чижова и др., 2019; Чижова и др., 2020; Chizhova et al., 2019).

Данная работа является вторым этапом исследования по изучению золоторудных месторождений, когда в общей схеме экспресс-анализа объекта оценки проходит уточнение его подтипа, если он был отнесен ранее системой к Au-Ag эпитермальному типу. Для описания золотосеребряных эпитермальных рудных объектов использовались геохимические характеристики штуфных проб (52 элемента: Li, Be, P, Sc, Ti, V, Cr, Mn, Co, Ni, Zn, Ga, As, Se, Rb, Sr, Y, Zr, Nb, Mo, Ag, Cd, In, Sn, $\mathrm{Sb}, \mathrm{Te}, \mathrm{Cs}, \mathrm{Ba}, \mathrm{La}, \mathrm{Ce}, \mathrm{Pr}, \mathrm{Nd}, \mathrm{Sm}, \mathrm{Eu}, \mathrm{Gd}, \mathrm{Tb}, \mathrm{Dy}, \mathrm{Ho}, \mathrm{Er}, \mathrm{Tm}, \mathrm{Yb}, \mathrm{Lu}, \mathrm{Hf}, \mathrm{Ta}, \mathrm{W}, \mathrm{Tl}, \mathrm{Pb}, \mathrm{Bi}, \mathrm{Th}, \mathrm{U}$, $\mathrm{Au}, \mathrm{Cu})$ и коллекции образцов руд (146 образцов) по 26 месторождениям и рудопроявлениям золота Северо-востока России различных их подтипов (табл. 1). Результаты анализов (AAS, ICP-MS и РФА) выполнены в аналитической лаборатории ИГЕМ РАН.

Логико-информационное моделирование на базе машинного обучения для анализируемых групп объектов обеспечивает выделение множество информативных признаков с указанием их разделяющих весов и диапазонов изменения значений (интервалов-индикаторов), типичных для месторождений золота конкретного формационного типа (Чижова, 2010).

Логико-информационное моделирование состоит из трех этапов:

1. определение пределов изменения свойств (интервалов - индикаторов), характеризующих группы изучаемых объектов;

2. количественная оценка их информативности (разделяющих свойств);

3. построение правила отнесения объекта к одной из изучаемых групп на основе полученных оценок.

Логико-информационные модели на базе машинного обучения представляют собой множество информативных признаков (элементов), с указанием их разделяющих весов и диапазонов изменения их значений (интервалов-индикаторов), типичных для каждой из групп месторождений (табл. 1).

Чтобы использовать модели для определения рудноформационного подтипа месторождения по образцу, необходимо рассчитать вес образца для каждой модели (суммируются разделяющие веса тех элементов, для которых значение в образце попадает в интервал-индикатор, типичный для этого подтипа).

Принимается следующее решающее правило: месторождение относится к тому типу, для которого вес будет иметь максимальное значение.

\section{Результаты анализа}

Математическая обработка данных позволила нам составить логико-информационные модели для анализируемых групп Au-Ag эпитермальных месторождений, как наборы из 52 признаковэлементов с интервалами-индикаторами и весами в диапазоне от 0 до 1. Пример интерваловиндикаторов для первых десяти элементов представлен на рисунке 1.

Анализировалась база данных проб и образцов руд по 26 месторождениям и рудопроявлениям Au-Ag эпитермальной формации Северо-Востока России. Полученные правила для принятия решения позволили надежно определить принадлежность проб к выделенным группам месторождений из базы данных. При использовании соответственно 146 проб (для каждой из 11 групп соответственно по 5, 26, 6, 13, 20, 13, 6, 6, 15, 11, 13 проб, см. табл. 1) в таблице обучения, получены правила, позволившие надежно идентифицировать пробы (6 ошибок из 146 проб, качество распознавания =0.96). Поэтому их можно использовать для оценки новых прогнозных площадей.

Для выделения 11 подтипов эпитермальных руд (табл. 1) на основе анализа 146 проб для каждой группы выделились наиболее информативные: 1 : Ti, Zr, Sm, Ta, Pb; 2 : Sc, Zn, Ba, Eu; 3: Rb, Mo, $\mathrm{Sn}, \mathrm{Ba}, \mathrm{Hf}, \mathrm{Th}$; 4: Rb, Sb,Ce; 5: Se, In, Sn, Tl; 6: P, Mn, As, Sb, Pr; 7: Mn, As, Cs, Pb, Au, Cu; 8: V, Zn, $\mathrm{Ag}, \mathrm{Cd}, \mathrm{Sn}, \mathrm{Cu}$; 9: Be, Mn, As, Rb; 10: Mn, Zn, W, U, Au, Cu; 11: Cr, In, Hf, Ta, Th. Система моделей основана на широком наборе элементов и репрезентативной базе данных эталонных месторожде- 


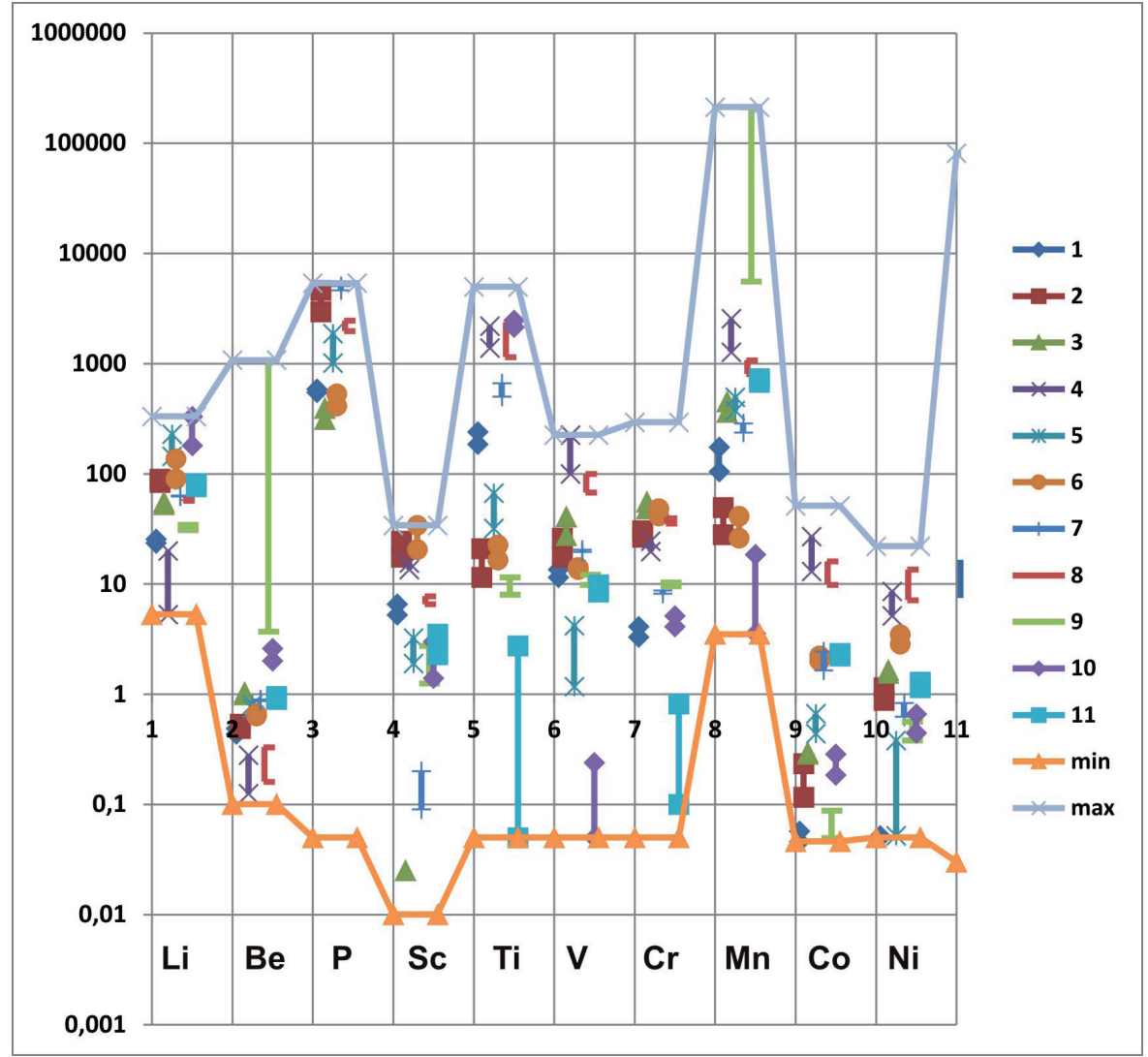

Рис. 1. Интервалы-индикаторы для автоматизированной типизации $\mathrm{Au}-\mathrm{Ag}$ эпитермальных месторождений (элементы 1-10).

Fig. 1. Intervals-indicators for automated typification of Au-Ag эпитермальных deposits (elements 1-10).

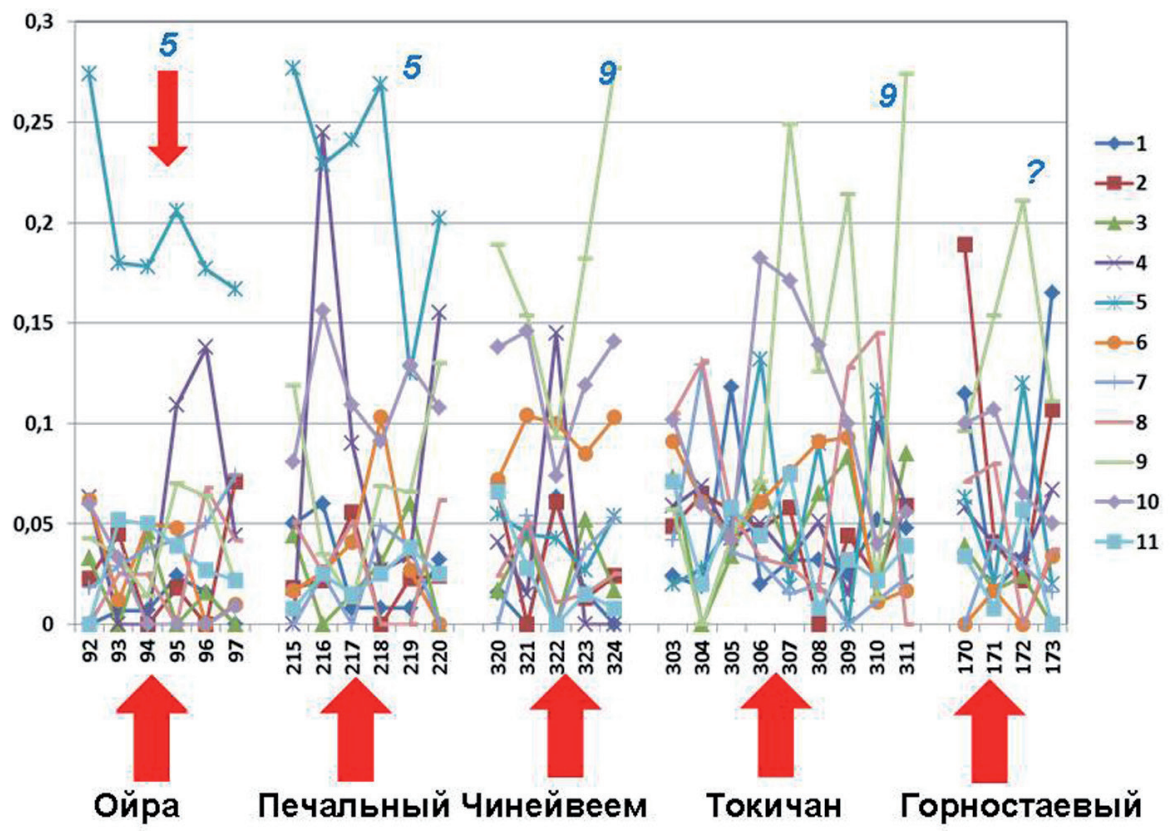

Рис. 2. Результат определения подтипа Au-Ag-эпитермальной формации (1-11) для экспертируемых объектов: Ойра, Печальный, Чинейвеем, Токичан, Горностаевый.

Fig. 2. Result of Au-Ag epithermal formation subtype (1-11) definition for the objects under study: Oyra, Pechalny, Chineyveem, Tokichan, Gornostaevy. 
ний. Это позволяет использовать их при изучении и оценке золоторудных месторождений в аналогичных рудоносных провинциях.

\section{Экспресс-оценка новых проявлений золота}

Логико-информационные модели использовались для экспресс-оценки новых проявлений золота перспективных площадей Арктической зоны, находящихся в сходных геологических условиях. Для определения рудноформационного подтипа нового рудопроявления по штуфным пробам, рассчитывалось значение функции принадлежности проб к анализируемым группам эталонов как суммарный вес индикаторных данных проб последовательно для каждой модели (суммируются разделяющие веса тех элементов, для которых значение в пробе попадает в интервал-индикатор соответствующего рудноформационного подтипа). Оцениваемый новый объект относится к тому рудноформационному подтипу, для которого суммарный вес индикаторных данных примет максимальное значение среди всех вычисленных суммарных весов по каждому рудноформационному подтипу.

В качестве исходных данных по новым экспертируемым объектам использовались геохимические данные по золоторудным объектам: Ойра (6 проб), Печальный (6 проб), Чинейвеем (5 проб), Токичан (9 проб), Горностаевый (4 пробы). Компьютерный анализ по экспресс-оценке перечисленных выше рудопроявлений проводился с использованием разработанной в ИГЕМ РАН экспертной системы в виде Excel-модуля (Чижова и др., 20202), куда пользователю предоставляется возможность ввести свои данные по экспертируемому объекту и получить оценку в графической и табличной форме (рис. 2).

На первом этапе работы все они были отнесены системой к Au-Ag эпитермальной формации (Чижова и др., 2019). На втором этапе работы системы использовались логико-информационные модели подтипов данной формации (см. табл. 1).

Построенные решающие правила позволили идентифицировать новые площади Арктической зоны РФ. Ойра - все 6 проб были отнесены к группе 5 (см. табл. 1). Печальный - из 4 проб, отнесенных к Au-Ag эпитермальному типу, 3 отнесены к группе 5. Чинейвеем - из 5 проб 4 отнесены к группе 9. Токичан - из 9 проб 4 отнесены к группе 9. Горностаевый - для его идентификации (4 пробы) данных не достаточно, чтобы проследить тенденцию изменения интегральных характеристик.

В итоге: Ойра и Печальный относятся к группе 5; Чинейвеем относится к группе 9; Токичан относится к группе 9. Результат представлен на рисунке 2 и совпал с мнением эекспертов.

\section{Заключение}

Рассчитаны логико-информационные модели по геохимическим данным для 11 подтипов месторождений Au-Ag-эпитермальной формации. Построенные решающие правила позволили надежно идентифицировать рудноформационный подтип Au-Ag эпитермальных месторождений (качество распознавания $96 \%$ ).

Разработана экспертная система в виде Excel-модуля для автоматизированной типизации новых золоторудных объектов.

Предложенная процедура экспресс-оценки золоторудных месторождений, включающая в себя использование логико-информационных моделей, показала высокую результативность и может быть применена в сходных геологических условиях при изучении и оценке новых золоторудных объектов, в том числе и в арктической зоне России.

Работа выполнена при финансовой поддержке РФФИ (грант № 18-05-70001).

\section{Литература}

4. Волков А.В., Сидоров А.А., Савва Н.Е., Колова Е.Е., Чижова И.А., Мурашов К.Ю. Геохимические особенности вулканогенного рудообразования в северо-западном сегменте Тихоокеанского рудного пояса // Вулканология и сейсмология. 2017. № 6. С. 3-20. DOI: 10.7868/S0203030617060013.

5. Поднебесных А.В., Хафизов А.Р. Методика экспресс-оценки выбора объекта-аналога для залежей углеводородного сырья на основе их геологических признаков // Проблемы сбора, подготовки и транспорта нефти и нефтепродуктов. 2019. № 3. C. 9-18. DOI: 10.17122/ntj-oil-2019-3-9-18. 
6. Чижова И.А. Логико-информационное моделирование при прогнозно-металлогеническом анализе перспективных площадей // Труды ИГЕМ РАН: новая серия. Вып. 4: Современные проблемы рудной геологии, петрологии, минералогии и геохимии М. Изд-во: ИГЕМ РАН. 2010. С. 59-84. ISBN 978-5-88918-019-7.

7. Чижова И.А., Волков А.В., Шелястина Е.В. Автоматизированная типизация золотосеребряных эпитермальных рудных месторождений на основе логико-информационного анализа // Физикохимические и петрофизические исследования в науках о Земле. Двадцать первая междунар. конф., Москва, 21-23, Борок, 25 сентября 2020 г. Мат. конференции. М. Изд-во: ИГЕМ РАН. 2020. С. $270-277$. ISBN 978-5-88918-059-3/ ISSN 2686-8938.

8. Чижова И.А., Волков А.В., Лобанов К.В., Шелястина Е.В. Экспресс-оценка месторождений золота Арктической зоны России по геохимическим данным с использованием логико-информационных моделей // Труды Ферсмановской научной сессии ГИ КНЦ РАН. 2020. 17. С. 552-557. DOI: 10.31241/FNS.2020.17.107.

9. Чижова И.А., Лобанов К.В., Волков А.В. Логико-информационные модели для прогноза и оценки новых месторождений золота в Арктической зоне России // Арктика: экология и экономика. 2019. № 4 (36). C. 107-117. DOI: 10.25283/2223-4594-2019-4-107-117.

10. Chizhova I., Lobanov K., Volkov A. Logical-Information Models for prediction and express-evaluation of new gold ore deposits in the Arctic zone of Russia // 19th International Multidisciplinary Scientific GeoConference SGEM 2019, www.sgem.org, SGEM2019 Conference Proceedings, 30 June -6 July. 2019. Albena, Bulgaria. V. 19. Informatics, Geoinformatics and Remote Sensing. Issue 2.1. Informatics. Geoinformatics. P. 935-942. ISBN 978-619-7408-79-9 / ISSN 1314-2704. DOI: 10.5593/sgem2019/2.1/S08.121.

11. Kaplan U.E. and Topal E., A New Ore Grade Estimation Using Combine Machine Learning Algorithms // Minerals. 2020. V. 10. Issue 10. Article 847. P. 1-17. DOI: 10.3390/min10100847.

12. Schnitzler N.; Ross P.-S., Gloaguen E. Using machine learning to estimate a key missing geochemical variable in mining exploration: Application of the Random Forest algorithm to multi-sensor core logging data // Journal of Geochemical Exploration. 2019. V. 205. P. 106-344. DOI: 10.1016/j.gexplo.2019.106344.

13. Zhang S.-H., Xiao K.-Y., Chen J.-P., Xiang J., Cui N., Wang X.-N. Development and future prospects of quantitative mineral assessment in China // China Geology. 2019. V. 2. Issue 2. P. 198-210. DOI: 10.31035/cg2018097. 